\title{
LIII. Experimental researches on the temperature of the sun
}

\section{F. Rosetti}

To cite this article: F. Rosetti (1879) LIII. Experimental researches on the temperature of the sun, Philosophical Magazine Series 5, 8:51, 438-449, DOI: $10.1080 / 14786447908639712$

To link to this article: http://dx.doi.org/10.1080/14786447908639712

曲 Published online: 13 May 2009.

Submit your article to this journal ๘

Џ Article views: 2

Q View related articles ¿ 
siderable experience proved this method to be the most expeditious, convenient, and accurate of those usually employed for the separation of these metals.

The experiments were made in Prof. Galloway's laboratory at the Royal College of Science.

October 1879.

LIII. Experimental Researches on the Temperature of the Sun. By F. RosetT, Professor of Physics in the University of Padua.

[Continued from p. 332.]

IV. Calculation of the Constants of the Formula in order to render it applicable to the Experiments made with Pile No. 1.

THE object of my investigation was to ascertain the tem1 perature of the sun by applying the formula to experiments made on solar radiation. In these, and in many other experiments made on the radiation of very hot bodies, I employed the pile No. 1. The constants $a$ and $b$, determined for pile No. 2, had then to be modified in such a manner that the same formula, with the new values of the two constants, could be applied to the experiments made with pile No. 1 . For this purpose I made experiments by placing the two piles successively in front of the Leslie's cube, kept at a constant temperature of $312^{\circ} \mathrm{C}$.

Pile No. 1 produced $28^{\circ}$ deflection,

giving

Pile No. 2 " $78^{\circ}$,

$$
\frac{\text { No. } 1}{\text { No. } 2}=\frac{28}{78}=0.359 \text {; }
$$

i. e. pile No. $1=0.359$ No. 2 .

Thus, in order to adapt the preceding formula to pile No. 1 , the constants $a$ and $b$ had to be multiplied by 0.359 . I was desirous, however, of so expressing the formula, that by means of it the thermal effect of the sun on pile No. 1 could be directly compared with the effect of the radiation from the hot body observed under the same angle as the sun, $i . e$. $32^{\prime} 3^{\prime \prime} \cdot 6$. By placing the pile with its face 134 millims. from the radiating surface of the Leslie's eube, which, by the interposition of a diaphragm, was limited to a circle of 32.65 millims. diameter, I obtained a deflection of 98.5 divisions on the galvanometer. In order that the radiating surface should be at the same angle as the sun, the pile should have been placed at a distance of 3.499 metres. By making use of the law of inverse squares, it is obvions that the deflection on the galva- 
nometer should have been $0 \cdot 1444$ division. Thus we have for pile No. 1,

$$
\text { No. } 1=\frac{0 \cdot 1444}{98 \cdot 5}=0 \cdot 0014665 \text {. }
$$

The constants $a$ and $b$ have therefore to be multiplied by the two reduction coefficients 0.359 and 0.0014665 in order to obtain the new constants $m$ and $n$. I have used the formula thus obtained in my experiments with pile No. 1. For this pile, then, we have the following formula :-

$$
\begin{aligned}
y & =m \mathrm{~T}^{2}(\mathrm{~T}-\theta)-n(\mathrm{~T}-\theta), \\
\log m & =1 \cdot 2466088-10, \\
\log n & =5 \cdot 5254189-10,
\end{aligned}
$$

on condition that the pile be placed at a distance from the radiating body equal to $107 \cdot 17$ times the diameter of the body, so that it shall appear, like the sun, at an angle of $31^{\prime} 3^{\prime \prime} \cdot 6$.

\section{Verification of the Applicability of the Formula for Tempe- ratures above $300^{\circ}$.}

Calorimetrical Experimerts. - These experiments were made in order to ascertain whether the formula continues to represent correctly the thermal effect of the radiation of bodies when their temperature exceeds $300^{\circ}$. The first experiment was made with a sheet of copper covered with lampblack and heated by a spirit-lamp. This was one of the sources of heat employed by Melloni, according to whom the copper has a temperature of about $400^{\circ}$. Other physicists affirm the temperature to be $390^{\circ}$. On introducing the value of the deflection on the galvanometer, obtained with pile No. 1, into the formula, I obtained, from two successive experiments, numbers between $390^{\circ}$ and $400^{\circ}$. As the temperature of the sheet was probably slightly different in the two experiments, I regarded the result of this first trial as satisfactory. It was necessary, however, that some more conclusive experiments should be made at temperatures which were higher, but which could nevertheless be determined by calorimetric methods. I therefore took a ball of copper heated to redness, the temperature of which was estimated by means of a calorimeter constructed for high temperatures. I suspended the copper ball by means of a fine platinum wire in the flame of a large $W$ iessnegg burner. The centre of the ball was in the line passing horizontally through the centres of the holes of the serew-nuts and through the centre of the face of the pile No. 1. In the circuit of the latter was included, as usual, the Wiedemann's galvanometer; and the temperature of the ball was considered to be constant when the galvanometric deflection remained 
constant for a certain time. Then, at a given signal, an assistant pushed the flame aside, and another assistant placed the calorimeter-receiver under the ball and immediately raised it, so that the ball dipped into the water of the calorimeter. The work was all done so quickly that there was little fear about the cooling of the ball between the removal of the flame and the immersion in water.

The calorimeter employed was a double-walled vessel, provided with a thermometer (protected by a brass sheath) and a brass stirrer ; the vessel also had a wooden handle, by means of which it could readily be moved. The thermometer was graduated into fifths of a degree, and had been compared with a standard. The water equivalent of the calorimeter with the thermometer and agitator had been determined by preliminary experiments. Half a litre of distilled water was poured into the vessel. If we call

$Q$ the weight of the water poured into the vessel,

$q$ the water equivalent of the vessel with thermometer and stirrer,

$t_{1}$ the temperature of the water before the immersion of the ball,

$t_{2}$ the temperature of the water after the immersion of the ball.

$t$ the temperature of the heated ball,

$p$ the weight of the ball,

$c$ the mean specific heat of copper between $t_{1}$ and $t_{2}$, we have

$$
(\mathrm{Q}+q)\left(t_{2}-t_{1}\right)=p c\left(t-t_{2}\right)
$$

from which the value of $t$ can be calculated.

The quantity $c$ has been determined by Bède (Wullner, Physik, vol. iii. p. 436,1872$)$, who found

$$
c=0 \cdot 0910+0 \cdot 000023\left(t+t_{2}\right) \text {. }
$$

The experiments from which Bede established this formula did not extend beyond $247^{\circ}$. For want of a better, I had to assume that the same formula might be employed even for much higher values of $t$. Of the numerous experiments which I made I shall only quote two.

In the first the surrounding temperature was $11^{\circ}:-$

$$
\begin{array}{ll}
\mathrm{Q}=498 \cdot 2, & q=32 \cdot 5, \quad t=10 \cdot 58, \\
t_{2}=29 \cdot 18, & p=123.33 ;
\end{array}
$$

by the two preceding formulæ we have

In the second:-

$$
c=0 \cdot 1092, \quad t=762^{\circ} \cdot 1 \text {. }
$$

$$
t_{1}=11 \cdot 15, \quad t_{2}=29 \cdot 60, \quad t=756^{\circ} \cdot 63 .
$$


Calculation of the Readings of the Galvanometer.-Four readings were taken on the galvanometer before the ball was immersed in the water. The first reading, with an open circuit, gave the zero-point; the second was made with a closed circuit, the pencil of heat-rays being shut off by means of the double screen. These two readings were always nearly identical, showing that the case protected the pile effectually.

In the first of the experiments mentioned the readings

\begin{tabular}{|c|c|}
\hline were:- & $\begin{array}{l}\text { Circuit open } \\
\text { Circuit closed }\end{array}$ \\
\hline in the se & 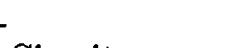 \\
\hline & Cir \\
\hline
\end{tabular}

The difference 1.5 in the two readings represents the effect of the medium upon the face of the pile which receives the radiation, the window of the case being open; but it might also arise from some slight thermo-electric current induced by contact with the rheophore. Whatever may be the cause of the slight deflection, it can easily bo eliminated by subtracting the second reading from the following readings which give the deflection produced by the radiation.

The third reading affords a measure of the thermal effect of the flame; the difference between the fourth and the second reading gives the total effect of the radiation of the hot ball and of the half of the flame which surrounds it. Thus the thermal effect produced on the pile by the radiation of the ball can easily be found. It is well known that the blue flames of Bunsen's burners are almost entirely diathermanous. Consequently it is only necessary to subtract the number of divisions which represent the thermal effect of the front part of the flame (which on account of its feeble emisssive power is always small in comparison with the number of divisions obtained by the radiation of the heated body) from the difference between the fourth and second reading, which gives the combined effect of the flame and the ball.

In the first of two calorimetric experiments the difference between the fourth and second readings was equal to 248.9 divisions, which, on subtracting 13.6 divisions, the thermal effect of that part of the flame which could radiate towards the pile, gives us 235.3 as the measure of the thermal effect of the ball on the face of pile No. 1 .

The distance from the centre of the ball to the centre of the pile was 185 millims.; and 66 millims. was the distance from the same centre to the screen, the smallest hole in which was 15 millims. in diameter. The diameter of the ball was 30 millims. It can be shown by a simple calculation that every

$$
\text { Phil. Mag. S. 5. Vol. 8. No. 51. Dec. } 1879 . \quad 2 \mathrm{H}
$$


part of the pile received rays, not from the whole of the sphere, but from a spherical segment, the thermal effect of which was equal to the radiation which a circular disk of 21.42 millims. diameter would produce if placed so that the back point made a tangent to the sphere, i. e. at 170 millims. from the face of the pile. By the law of inverse squares, we find that if at 170 millims. distance the thermal effect of the radiation of the ball was 235.9 divisions of the galvanometer, then at 2296.5 millims. it should have been 1.322 division.

There are two methods of comparing the results of the calorimeter experiments with the galvanometer observations; and they yield similar results. We can either introduce the values $\mathrm{T}$ and $\mathrm{T}-\theta$ (given by the calorimeter experiments) into the formula, and obtain thus the value of $y$, in which case we should have

giving

$$
\begin{aligned}
\mathrm{T} & =273+762 \cdot 1=1035 \cdot 1, \\
\theta & =273+11 \cdot 0=284 \cdot 0, \\
\mathrm{~T}-\theta & =751 \cdot 1,
\end{aligned}
$$

or we can equally well introduce into the formula the value $y=1.322$ given by the galvanometer observations, and deduce from this the value of $T$ and then of $t$. Doing this and remembering that the surrounding temperature was $11^{\circ} .0$, and consequently

$$
\begin{array}{ll}
\theta=273+11 \cdot 0=284, \\
\text { we obtain } & \mathrm{T}=1019 \cdot 0, \quad t=746.0 .
\end{array}
$$

Comparing the two values of $y$ and of $t$,

$$
\begin{aligned}
& \text { C. } \\
& y=1 \cdot 3943 \text { and } 1 \cdot 322, \\
& t=762 \cdot 1 \quad \text { and } 746 \cdot 0,
\end{aligned}
$$

we see that they do not differ much; but quite enough to show that the formula would not be applicable at high temperatures. It struck me that the slight difference might possibly be owing to the emissive power of the red-hot ball, and that, since the experiments which were employed for the calculation of the constants of the formula had been made with a surface covered with lampblack, all discrepancies would probably have disappeared, if even at high temperatures the radiating surface were covered with lampblack. I invented, therefore, a method of comparing the thermal effect of very hot bodies whose surface is bare with the same bodies when equally hot but with their surfaces covered with lampblnck; so that, on comparing the two values, I obtained a number representing the emissive power of the plain body compared with the emissive 
power of lampblack; and taking the latter as unity, I thus obtained the emissive power of the body under experiment.

In the following section I shall make use of this method. For the present, I need only mention that I obtained from my experiments the number 0.943 to represent the emissive power of copper surrounded by a flame.

In the calorimetric experiments already mentioned, the bare ball of copper gave

$$
y=1 \cdot 322 \text {. }
$$

If this ball had been covered with lampblack, the thermal effect would have been

$$
y=\frac{1 \cdot 322}{0.943}=1 \cdot 402 ;
$$

and the formula would give the value

The values

$$
t=763.6 \text {. }
$$

$$
\begin{aligned}
& 1 \cdot 394 \text { and } 1 \cdot 402 \text {, } \\
& 762 \cdot 1 \text { and } 763 \cdot 6
\end{aligned}
$$

are near enough to be satisfactory; and we may therefore conclude that the formula is applicable to high temperatures, provided that the radiating surface be lampblack, or that the specific emissive power of the radiating surface be introduced into it. I have made my description of this experiment very minute, in order to give an exact idea of the manner in which I have conducted these researches. I made many other calorimetric experiments, from which I obtained satisfactory results.

VI. Method of determining the Specific Emissive Power of Bodies at High Temperatures.

I have invented a very simple and exact method of determining the specific emissive power of bodies at high temperatures. Every body knows the form assumed by the flame of a Bunsen's burner when the air is freely admitted. By my researches on the different shapes of these flames ("Sulla Temperatura delle Fiamme," Atti del R. Istituto Veneto, vol. iii. 1877), I have shown that in the higher part lying between the apex of the interior cone and the summit of the exterior envelope the temperature is not higher than $1200^{\circ}$. A body placed in this space would have a temperature lower than that of the flame, dependent upon several causes-viz. the mass of the body, the specific heat, the conductivity, the emissive power, and the conductivity of the wire or rod employed to support the body. Nevertheless it is certain that, if the flame remains constant, the same body placed in the same position will have the same temperature in two successive experiments.

Now, if in one experiment the surface of the body be bare $2 \mathrm{H} 2$ 


\section{4}

\section{Prof. F. Rosetti's Experimental Researches}

and in the other covered with lampblack, it is evident that we thus have the means of obtaining the emissive power of the body under experiment compared with that of lampblack. The body must be placed exactly in the part of the flame mentioned; otherwise the lampblack will rapidly oxidize and expose the metallic surface (see fig. 2).

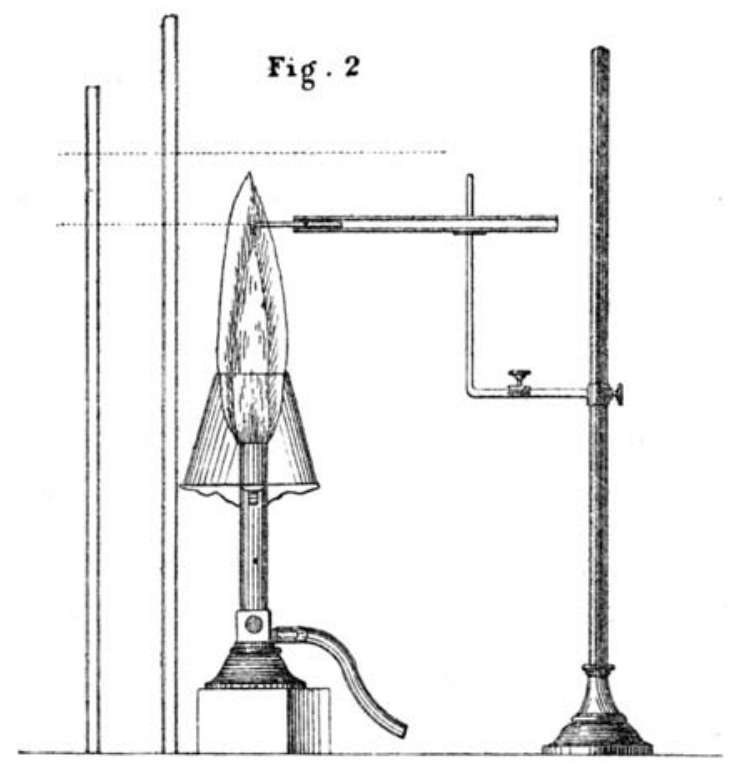

I made the bodies upon which I experimented into disks of 10 millims. diameter. They were kept in the centre of the flame by a wire or rod of the same substance held in a porcelain tube.

The results obtained for some of the bodies were as follows:-

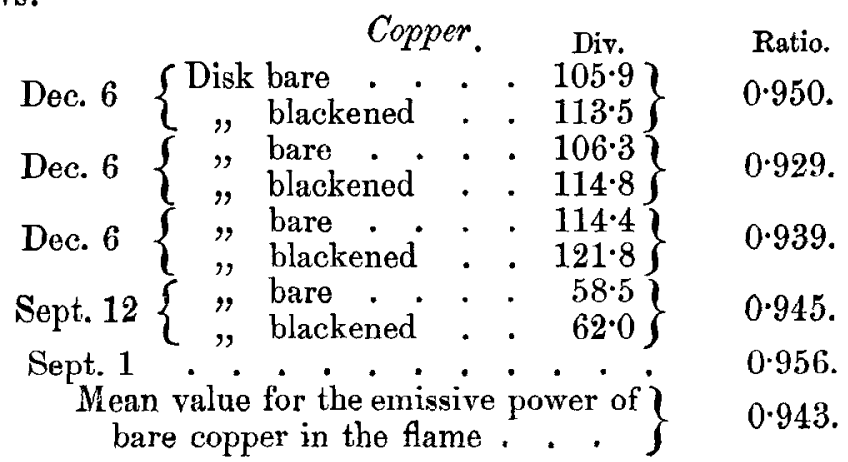




\section{Iron.}

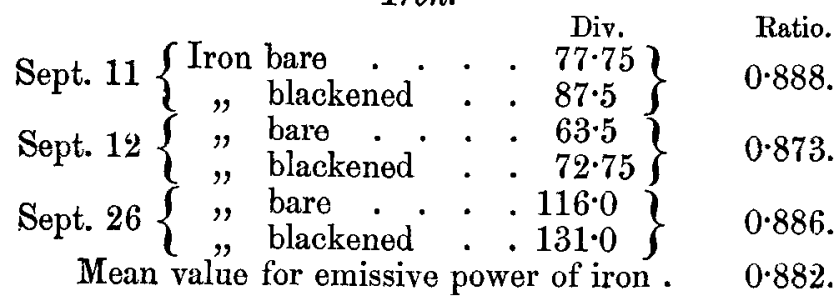

\section{Platinum.}

\begin{tabular}{|c|c|c|c|c|}
\hline & & & & \\
\hline Sept. 11 & Platinum & bare. & $\begin{array}{l}\text { Div. } \\
35 \cdot 5\end{array}$ & $\begin{array}{c}\text { Iiatio. } \\
0.364 .\end{array}$ \\
\hline & $"$ & $\begin{array}{l}\text { blackened } \\
\text { bare. }\end{array}$ & $\begin{array}{l}97 \cdot 5 \\
18 \cdot 75\end{array}$ & \\
\hline Sept. a & " & blackened & $55 \cdot 5$ & 0.338 \\
\hline Sept. 26 & " & bare . & $36 \cdot 0$ & 0.360 \\
\hline & " & $\begin{array}{l}\text { blackened } \\
\text { bare... }\end{array}$ & $\begin{array}{r}100^{\circ} 0 \\
. \quad 81 \cdot 0\end{array}$ & \\
\hline $\mathrm{Me}_{\mathrm{e}}$ & $"$ & blackened & $240^{\circ} 0$ & $0 \cdot 3$ \\
\hline
\end{tabular}

Cylinders of Magnesium Oxychloride.-As I proposed to make experiments upon the radiation of small cylinders of magnesium oxychloride when rendered incandescent by the oxyhydrogen flame, I wished to determine also the emissive power of this substance. The cylinders had a diameter of about 6 millims. I placed the one upon which I meant to experiment in a horizontal position so that its end penetrated into the Bunsen flame and occupied the same position as the disks in the preceding experiments ; and I obtained the following results :-

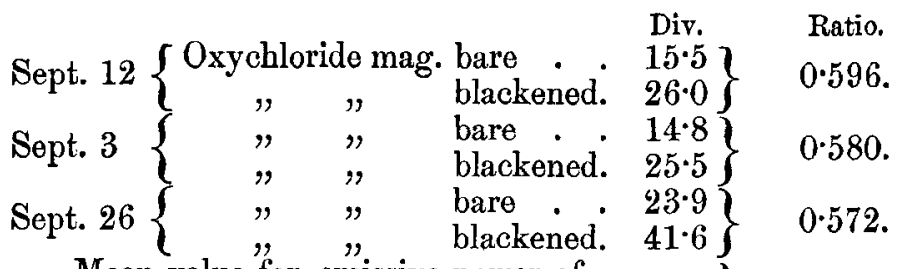

Mean value for emissive power of magne- $\} \quad 0.584$. sium oxychloride....... .

Therefore, at high temperatures, the emissive powers of $\mathrm{Cu}, \mathrm{Fe}, \mathrm{Pt}$, and $\mathrm{Mg}$. oxychloride are represented by the numbers $0.943,0.882,0.350,0.584$. 
VII. Verification of the Applicability of the Formula to Temperatures above $800^{\circ}$.

If we call $\epsilon$ the specific emissive power of the radiating bodies, the formula becomes

$$
y=m \epsilon \mathrm{T}^{2}(\mathrm{~T}-\theta)-n(\mathrm{~T}-\theta) ;
$$

and if the experiments be made with lampblack, $\epsilon=1$.

In order to ascertain whether this formula be also applicable when the temperatures are higher than those used in the calorimetric experiments, I used the same experiments as those by which $\epsilon$ was determined, commencing with copper. I made use successively of three disks of copper with the same diameter of 10 millims. The first had a thickness of 1 millim., the second of 2 millims., and the third of 3 millims. It is certain that each different disk when placed in the flame acquires a different temperature, the smallest attaining a higher temperature than the other two: if a disk were made any smaller (as, for example $\frac{1}{4}$ of a millimetre), it would soon become red hot and begin to melt. Now we know the melting-point of copper is $1050^{\circ}$; and therefore we may conclude that the smallest of the three disks acquires in the flame a temperature of about $1000^{\circ}$. The following results were obtained :-

Sept. 3.-Copper disk blackened, with thickness 1 millim., diameter 10 millims., placed at 438 millims. from the pile; the surrounding temperature being $28^{\circ} \mathrm{C} . ; \theta=273+28=301^{\circ}$; the deflection on the galvanometer $=15 \cdot 9$. Calculating the deflection on the galvanometer, supposing the pile were at a distance of $107 \cdot 17+10$ millims., we obtain

$$
y=2 \cdot 6554 \text { divisions. }
$$

Introducing this value into the formula, as in the case of $E=1$, we have

$$
\mathrm{T}=1260^{\circ}, \quad t=987^{\circ} .
$$

In another experiment I obtained :-

Sept. 26.-Copper blackened; thin disk ( 1 millim.); distance from the pile 163 millims.; surrounding temperature $18^{\circ} ; \theta=291^{\circ}$; deflection of the galvanometer $=108 \cdot 0$ :

$$
y=2 \cdot 498, \quad \mathrm{~T}=1233^{\circ} \cdot 5, \quad t=960^{\circ} \cdot 5 \text {. }
$$

I made two experiments with the disk of thickness 2 millims.:-

Dec. 1.-Copper blackened; thickness of disk 2 millims.; distance from the pile 150 millims.; surrounding temperature $11^{\circ} ; \theta=284^{\circ}$; deflection of galvanometer 121.8 :

$$
y=2 \cdot 386
$$


the formula gives

$$
\mathrm{T}=1211^{\circ}, \quad t=938^{\circ} \cdot 0 .
$$

Dec. 6.-Distance from the pile 157 millims. ; $\theta=284^{\circ}$; deflection $=113 \cdot 5$.

$$
y=2 \cdot 432, \quad \mathrm{~T}=1218^{\circ}, \quad t=945 .
$$

Disk of copper 3 millims. thickness:-

Dec. 1.- Iistance from the pile 150 millims.; $\theta=284^{\circ}$; deflection $=114 \cdot 3$ :

$$
y=2 \cdot 239, \quad \mathrm{~T}=1190^{\circ} \cdot 7, \quad t=917^{\circ} \cdot 7 .
$$

Dec. 6.-Distance from the pile 157 millims.

$$
y=2 \cdot 272, \quad \mathrm{~T}=1196^{\circ} \cdot 3, \quad t=923^{\circ} \cdot 3 .
$$

The temperatures $987^{\circ}$ and $960^{\circ}$ obtained with the thin disk, $938^{\circ}$ and $945^{\circ}$, with the medium disk, and $917^{\circ} \cdot 7$ and $923^{\circ} .3$ with the thickest disk, were most probably their true temperatures at the time of the experiment.

Iron.--The disk of iron was very thin, 10 millims. in diameter, and was covered with lampblack.

Sept. 26.-Distance from the pile 163 millims.; deflection $131 \cdot 0 ; \theta=291^{\circ}$ :

$$
y=3 \cdot 030, \quad \mathrm{~T}=1308^{\circ} \cdot 0, \quad t=1035^{\circ} \text {. }
$$

Platinum.-The disk of platinum was very thin ; diameter 10 millims.:

$$
y=3.847, \quad \mathrm{~T}=1410^{\circ}, \quad t=1147^{\circ} .
$$

Cylinder of O.rychloride of Magnesium.-Diameter $6 \cdot 1 \mathrm{mil}-$ linss.; distance 163 millims.; deflection 41.6 ; $\theta=291^{\circ}$ :

$$
y=4.091, \quad \mathrm{~T}=1432^{\circ} \cdot 5, \quad t=1159^{\circ} \cdot 5 \text {. }
$$

To sum up, we find that the disks of copper acquired different temperatures according to their thickness : the thinest disk attained the temperature of $987^{\circ}$, the next thicker one $945^{\circ}$, and the thickest $923^{\circ}$. The thin disk of iron reached the temperature of $1035^{\circ}$, the disk of platinum $1147^{\circ}$, and the cylinder of magnesium oxychloride $1160^{\circ}$. We can understand how the last-mentioned body may attain a higher temperature than any of the others; for, being non-metallic, it is not so good a conductor of heat as the others, and therefore does not give up as much of its heat to the metallic support or porcelain tube by means of which it is held.

Experiments made with a Cylinder of Magnesium Oxychloride rendered Incandescent by means of a Flame of Coal-gas and Oxygen.

The cylinder of magnesium oxychloride which I used in my experiments had a diameter of 6.1 millims. The flame om- 


\section{Experimental Researches on the Temperature of the Sun.}

ployed to heat the cylinder was very short; but the heat from it was so intense that the platinum flowed like wax. It must be understood that in all these experiments the second reading on the galvanometer was subtracted from the first-the latter representing the effect of the radiation of the cylinder and flame, the former the radiation of the flame and surrounding bodies. It should also be remembered that a double screen with a hole in it a little larger than the base of a cylinder was placed between the latter and the pile, so that the influence of surrounding bodies was very small. The following are the results which were obtained.

\section{First Series.}

Cylinder of Magnesium oxychloride bare ; diameter $6 \cdot 1$ millims. ; surrounding temperature $24^{\circ} .4$; distance from the pile 588 millims.

First experiment.-Deflection of the galvanometer $11 \cdot 2$ divisions.

We find by calculation that, if the distance of the pile had been $6 \cdot 1+107 \cdot 17$ millims. (in order to make the radiating surface appear as if at an angle of $32^{\prime} 3^{\prime \prime} \cdot 6$ ), the reading would have been $y_{1}=9 \cdot 051$ divisions. But if we remember that the emissive power of magnesium oxychloride is 0.584 , we find that, if the cylinder had been covered with lampblack (i.e. if its emissive power had been equal to 1), the thermal effect would have been equal to

$$
y=\frac{y_{1}}{\mathbf{E}}=\frac{9 \cdot 051}{0 \cdot 584}=15 \cdot 499 \text { divisions. }
$$

Introducing this value of $y$ into the formula, if $t_{1}=24^{\circ} \cdot 4$ we shall have $\theta=297^{\circ} \cdot 4$, and we thus obtain $\mathrm{T}=2169^{\circ}$ and $t=1896^{\circ}$.

Second experiment.--Under the same conditions as the first. Deflection $12 \cdot 3$ millims., giving $y_{1}=9 \cdot 9404$ millims.,

By the formula we obtain

$$
y=\frac{y_{1}}{\mathbf{E}}=\frac{\cdot y_{1}}{0.584}=17 \cdot 06
$$

$$
\mathrm{T}=2236^{\circ}, \quad t=1963^{\circ} \text {. }
$$

Third experiment.-Reading on galvanometer $12 \cdot 2$ divisions.

$$
\begin{aligned}
& y_{1}=9 \cdot 859, \quad y=16 \cdot 84, \\
& \mathrm{~T}=2227^{\circ} .5, \quad t=1954^{\circ} .5 .
\end{aligned}
$$

Second Series.

First experiment.-The light was dazzling. Distance from 
the pile 420 millims.; surrounding temperature $24^{\circ} 0$; reading on the galvanometer 31.6 divisions.

Calculated for the distance $6 \cdot 1+107 \cdot 17$,

$$
y_{1}=13.0 \text { divisions, } y=\frac{y_{1}}{0.584}=22 \cdot 25 \text {; }
$$

the formula gives

$$
\mathrm{T}=2440^{\circ}, \quad t=2167^{\circ} \text {. }
$$

Second experiment.-In this experiment I obtained a large deflection on the galvanometer, but the cylinder shone very brilliantly. Distance from the pile 420 millims. Deflection (mean of three experiments) $=42.0$ divisions. At the distance $107 \cdot 17+6 \cdot 1$ millims. we should have had

$$
\begin{gathered}
y_{1}=17 \cdot 68 \text { divisions, } \quad y=\frac{17 \cdot 68}{0.584}=29 \cdot 58, \\
\mathrm{~T}=2670^{\circ}, \quad t=2397^{\circ} .
\end{gathered}
$$

These two numbers, $2167^{\circ}$ and $2397^{\circ}$, although higher than those obtained in the first series, will not appear too high if we reflect that platinum immediately melted before the flame, and that the light emitted in the experiments of the second series was considerably greater than that emitted in those of the first. I think that all who have made researches of this nature will consider the results obtained to be satisfactory, and that there is reason to conclude that the formula

$$
y=m \mathrm{ET}^{2}(\boldsymbol{J}-\boldsymbol{\theta})-m(\mathrm{~J}-\boldsymbol{\theta})
$$

which has stood the tests so well up to $2000^{\circ}$, can confidently be applied to experiments made at higher temperatures, and that it can be employed to find the temperature of the sun.

[To be continued.]

LIV. On Magneto-Electric Induction. By FREDERICK Guthrie and C. V. Boys, Assoc. R. School of Mines*.Part I.

\section{[Plate XIII.]}

T $T$ is well known that the electric currents caused in a con1 ductor by relative motion between that conductor and a magnetic pole are in such a direction as to impose a drag upon such motion. An ideal friction (that is, one without recoil) is called forth ; and, accordingly, in the experiments sometimes called Arago's such current-friction exhibits itself in the pursuit of the moving element by the one which is free to move, though originally at rest. Again, the same current-

\footnotetext{
* Communicated by the Physical Society.
} 